\title{
Association between Sleep Time and Blood Pressure in Korean Adolescents: Cross-Sectional Analysis of KNHANES VII
}

\author{
Suk-Won Chang ${ }^{1(D)}$ and Ju-Wan Kang ${ }^{2, *}$ \\ 1 Department of Otorhinolaryngology, Jeju National University Hospital, Jeju 63241, Korea; \\ swjang37111@gmail.com \\ 2 Department of Otorhinolaryngology, Gangnam Severance Hospital, Yonsei University College of Medicine, \\ Seoul 06237, Korea \\ * Correspondence: juwankangmd@yuhs.ac
}

\section{check for}

updates

Citation: Chang, S.-W.; Kang, J.-W Association between Sleep Time and Blood Pressure in Korean

Adolescents: Cross-Sectional Analysis of KNHANES VII. Children 2021, 8, 1202. https://doi.org/10.3390/ children 8121202

Received: 23 November 2021

Accepted: 17 December 2021

Published: 18 December 2021

Publisher's Note: MDPI stays neutral with regard to jurisdictional claims in published maps and institutional affiliations.

Copyright: (c) 2021 by the authors. Licensee MDPI, Basel, Switzerland. This article is an open access article distributed under the terms and conditions of the Creative Commons Attribution (CC BY) license (https:// creativecommons.org/licenses/by/ $4.0 /)$.

\begin{abstract}
Background: Hypertension is highly related to sleep, and there have been a number of studies on sleep deprivation and the occurrence of hypertension. However, there is still insufficient research on the relationship between hypertension and various factors related to sleep. Thus, this study attempted to investigate the relationship between hypertension and sleep time-related variables in Korean adolescents. Methods: A total of 1470 adolescents (709 girls and 761 boys) between 12 and 18 years of age were enrolled through the Seventh Korea National Health and Nutrition Examination Survey (KNHANES VII). The systolic and diastolic blood pressure were measured. Sleep time-related variables such as sleep onset time, wake time, and sleep duration (weekday and weekend, each) were also investigated using a questionnaire. We performed multivariate regression analyses to determine the independent effects of the variables. Results: Systolic blood pressure was negatively correlated with the wake time $(\mathrm{r}=-0.081 ; p=0.002)$ and sleep onset time $(\mathrm{r}=-0.088 ; p=0.001)$ on weekends. There was a positive correlation between diastolic blood pressure and weekday sleep onset time $(\mathrm{r}=0.158 ; p=0.000)$ and weekend sleep onset time $(\mathrm{r}=0.184 ; p=0.000)$. The sleep duration on weekdays and weekends showed a negative correlation $(\mathrm{r}=-0.136 ; p=0.000, \mathrm{r}=-0.088 ; p=0.001$, respectively). In the multivariate linear regression analysis results, the sleep onset time on weekends was significantly correlated with elevated diastolic blood pressure. Conclusions: Delayed sleep onset time on weekends was significantly associated with increased diastolic blood pressure in Korean adolescents. Further investigation is needed to confirm the clinical significance of these findings.
\end{abstract}

Keywords: adolescent; hypertension; diastolic; blood pressure; sleep

\section{Introduction}

The prevalence of hypertension is increasing with economic development and is highly related to the occurrence of cardiovascular, urinary, and other diseases. There is also a growing interest in the prevention and treatment of hypertension [1-3]. In particular, the incidence of hypertension in adolescents has recently increased, which is a global problem leading to adult hypertension [4]. Therefore, it is important to reduce the occurrence of hypertension in adolescence through prevention and early detection such as lifestyle changes [5].

There is much ongoing research on sleep-related diseases, especially the effects of sleep deprivation on the occurrence of hypertension. The loss of sleep time has been reported as a risk factor for developing cardiovascular diseases such as hypertension or coronary heart disease [6-8]. In addition, in several studies on the association of hypertension incidence according to sleep time in adolescents, the deprivation of sleep time in adolescents is known as a significant risk factor for hypertension $[9,10]$. Several studies have been conducted on the total sleep time and the occurrence of hypertension. However, there is still insufficient research on the relationship between hypertension and sleep time-related variables such as the sleep onset time and wake time. 
Therefore, this study aimed to determine the association of sleep time related variables such as the sleep onset time with the systolic and diastolic blood pressure in Korean adolescents using data from the Seventh Korea National Health and Nutrition Examination Survey (KNHANES VII) 2016-2018.

\section{Materials and Methods}

\subsection{Study Population}

We used data from the seventh Korea National Health and Nutrition Examination Survey (KNHANES VII), 2016-2018 Korea Centers for Disease Control and Prevention. The questionnaire survey included health surveys and checkups conducted at the mobile screening center. The nutrition survey was conducted by personally visiting target households. We included the data of adolescents aged between 12 and 18 years. We excluded the subjects who did not complete the questionnaire, which included variables such as sleep-related data, smoking history, and alcohol history. In addition, we excluded subjects whose blood pressure was not measured. Finally, the data of 1470 adolescents (709 girls and 761 boys) aged between 12 and 18 years were included in the analysis. We obtained informed consent from the legal guardians of all the participants. This study was approved by the Institutional Review Board of the Jeju National University Hospital.

\subsection{Measurement of Variables}

Smoking and alcohol history were also investigated using self-reported questionnaires. After the subjects rested for $10 \mathrm{~min}$, four nurses from the Korea Centers for Disease Control and Prevention (ICC) specialized investigation team measured the systolic and diastolic blood pressure once in each adolescent. The blood pressure was measured thrice. Additionally, we determined the mean values of the second and third test results as the final systolic and diastolic blood pressure. The subjects' heights and weights were also measured. The sleep onset time and wake time on weekdays were measured using a questionnaire. Sleep onset time and wake time were investigated in actual time (24-h format). However, the sleep onset time after midnight was presented by adding the actual time after $24 \mathrm{~h}$ in case sleep onset time. For example, 1 a.m. is marked as 25 , and 2 a.m. is marked as 26. The sleep duration on weekdays was estimated from the sleep onset time and wake time in hour. The sleep onset time, wake time, and sleep duration during the weekend were also measured using the same method.

\subsection{Statistical Analyses}

We compared the two groups using the Student's $t$-test. A correlation analysis between systolic and diastolic blood pressure and sleep time-related variables was performed. We performed multivariate linear regression analysis with diastolic blood pressure as the dependent variable. For statistical analysis, SPSS statistical software package version 17 (SPSS Inc., Chicago, IL, USA) was used. In all analyses, the $p$-value was considered to be two-tailed and the statistical significance was set at $p<0.05$.

\section{Results}

A total of 1470 adolescents (709 girls and 761 boys) were included in the study. The mean systolic blood pressure was $111.7( \pm 9.8) \mathrm{mmHg}$ for boys and $106.0( \pm 8.9) \mathrm{mmHg}$ for girls; it was significantly higher in boys $(p<0.001)$. Conversely, no significant difference was observed between boys and girls in the case of diastolic blood pressure $(67.6( \pm 7.8) \mathrm{vs}$. $67.0( \pm 7.8) ; p=0.215)$. The sleep onset time, wake-up time, and total sleep duration were longer on weekends than on weekdays (Table 1). 
Table 1. Characteristics and clinical parameters of the study population.

\begin{tabular}{|c|c|c|c|c|c|c|}
\hline \multirow{2}{*}{ Variables } & & \multicolumn{3}{|c|}{ Total $(n=1470)$} & \multirow[b]{2}{*}{ Girl $(n=709)$} & \multirow[b]{2}{*}{$p^{\#}$} \\
\hline & & Range & Mean ( \pm SD) & Boy $(n=761)$ & & \\
\hline Systolic BP (mmHg) & & $81-156$ & $108.9( \pm 9.8)$ & $111.7( \pm 8.9)$ & $106.0( \pm 8.9)$ & $<0.001$ \\
\hline $\begin{array}{l}\text { Diastolic BP } \\
(\mathrm{mmHg})\end{array}$ & & $35-94$ & $67.3( \pm 8.4)$ & $67.6( \pm 7.8)$ & $67.0( \pm 7.8)$ & 0.215 \\
\hline Height $(\mathrm{cm})$ & & 114-189 & $164.7( \pm 8.7)$ & $169.1( \pm 8.6)$ & $160.0( \pm 5.9)$ & 0.001 \\
\hline Weight (kg) & & 28-111 & $58.2( \pm 13.4)$ & $62.4( \pm 14.4)$ & $53.7( \pm 10.4)$ & 0.001 \\
\hline \multirow[t]{3}{*}{ Week day } & Sleep onset time * & $22-26$ & $23.9( \pm 1.2)$ & $23.8( \pm 1.1)$ & $24.0( \pm 1.2)$ & 0.001 \\
\hline & Wake time * & $5-9$ & $6.9( \pm 0.6)$ & $6.9( \pm 0.6)$ & $6.8( \pm 0.6)$ & 0.001 \\
\hline & Sleep duration $\$$ & $3-10$ & $6.9( \pm 1.3)$ & $7.1( \pm 9.8)$ & $6.7( \pm 1.4)$ & 0.001 \\
\hline \multirow[t]{3}{*}{ Weekend } & Sleep onset time * & $22-26$ & $24.5( \pm 1.2)$ & $24.4( \pm 1.2)$ & $24.6( \pm 1.2)$ & 0.001 \\
\hline & Wake time ${ }^{*}$ & $5-9$ & $8.6( \pm 0.8)$ & $8.5( \pm 0.8)$ & $8.7( \pm 0.7)$ & 0.001 \\
\hline & Sleep duration $\$$ & $4-14$ & $8.8( \pm 1.6)$ & $8.7( \pm 1.6)$ & $9.0( \pm 1.6)$ & 0.001 \\
\hline
\end{tabular}

Abbreviations: BP, Blood pressure. * Sleep onset time and wake time are presented in actual time (24-h format). However, the sleep time after midnight was presented by adding the actual time after $24 \mathrm{~h}$ in case sleep onset time. For example, 1 a.m. is marked as 25 , and 2 a.m. is marked as $26 .{ }^{\$}$ Duration of sleep is presented in hours. ${ }^{~ M e a n ~ v a l u e ~ o f ~ t w o ~ g r o u p s ~ w e r e ~ a n a l y z e d ~ u s i n g ~ t h e ~ S t u d e n t ' s ~} t$-test.

Systolic blood pressure was negatively correlated with the waking up time $(\mathrm{r}=-0.081$; $p=0.002)$ and the time to sleep $(\mathrm{r}=-0.088 ; p=0.001)$ on weekends. There was a positive correlation between the diastolic blood pressure and weekday time to sleep $(r=0.158$; $p=0.000)$ and weekend time to sleep $(\mathrm{r}=0.184 ; p=0.000)$, and the weekday sleep time $(\mathrm{r}=-0.136 ; p=0.000)$ and the weekend sleep time $(\mathrm{r}=-0.088 ; p=0.001)$ were negatively correlated (Table 2).

Table 2. Correlation analysis of sleep-related factor with systolic and diastolic blood pressure.

\begin{tabular}{|c|c|c|c|c|c|}
\hline \multirow[b]{2}{*}{ Variables } & & \multicolumn{2}{|c|}{ Systolic BP } & \multicolumn{2}{|c|}{ Diastolic BP } \\
\hline & & $\begin{array}{l}\text { Correlation } \\
\text { Coefficient }\end{array}$ & $p$-Value & $\begin{array}{l}\text { Correlation } \\
\text { Coefficient }\end{array}$ & $p$-Value \\
\hline \multirow[t]{3}{*}{ Weekday } & $\begin{array}{l}\text { Sleep onset } \\
\text { time }\end{array}$ & 0.013 & 0.631 & 0.158 & $<0.001$ \\
\hline & Wake time & 0.002 & 0.953 & 0.009 & 0.721 \\
\hline & $\begin{array}{l}\text { Sleep } \\
\text { duration }\end{array}$ & -0.009 & 0.741 & -0.136 & $<0.001$ \\
\hline \multirow[t]{3}{*}{ Weekend } & $\begin{array}{l}\text { Sleep onset } \\
\text { time }\end{array}$ & 0.023 & 0.371 & 0.184 & $<0.001$ \\
\hline & Wake time & -0.081 & 0.002 & 0.015 & 0.567 \\
\hline & $\begin{array}{c}\text { Sleep } \\
\text { duration }\end{array}$ & -0.088 & 0.001 & -0.088 & 0.001 \\
\hline
\end{tabular}

Abbreviations: BP, Blood pressure. Bold number indicates statistical significance $(p<0.05)$.

Figure 1 shows the mean and standard errors of systolic and diastolic blood pressure according to each sleep time variable. In the case of sleep onset time, it can be seen that the value of standard error was not large. However, the width of the standard error tends to be larger on the left and right sides of the sleep time measurement than in the middle area, in the case of wake time and sleep duration. 

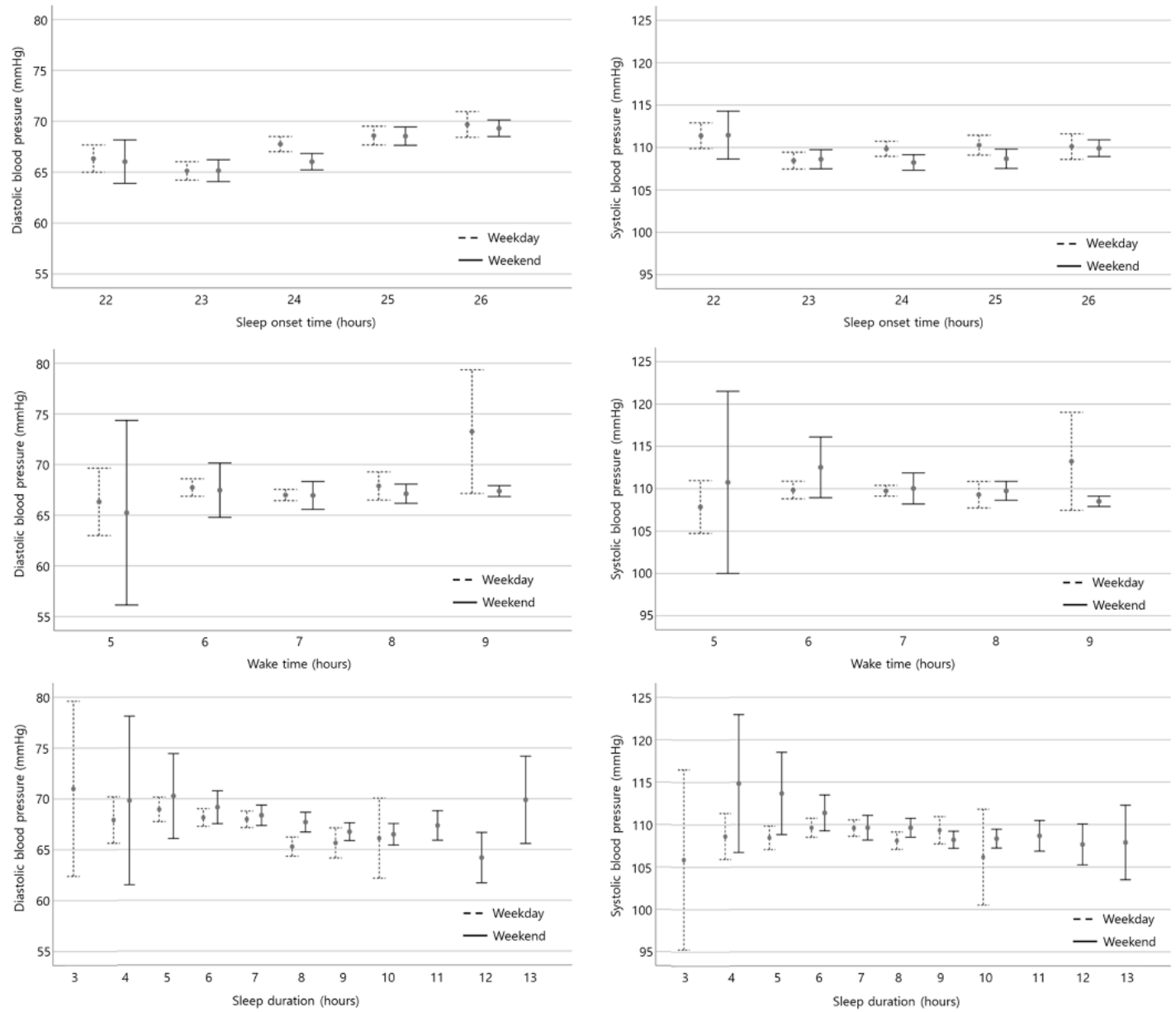

Figure 1. Mean (dot) and standard error (bar) according to each sleep variables. Sleep onset time and wake time are presented in actual time (24-h format). However, the sleep time after midnight was presented by adding the actual time after $24 \mathrm{~h}$ in case sleep onset time. For example, 1 a.m. is marked as 25 , and 2 a.m. is marked as 26.

Finally, we performed a multivariate linear regression analysis. When systolic blood pressure was considered as a dependent variable, the systolic blood pressure was significantly lower in girls than in boys $(B=-3.473,95 \%$ confidence interval $[C I] 2.337-4.610$; $p<0.001$ ), and the body weight was positively correlated with the systolic blood pressure ( $B=0.302,95 \%$ CI $0.258-0.346 ; p<0.001)$. However, no variables related with the sleep time showed any significant association (data not shown).

Table 3 shows the results of the multivariate linear regression analysis when diastolic blood pressure is the dependent variable. The diastolic blood pressure increased with age ( $\mathrm{B}=0.561,95 \% \mathrm{CI} 0.267-0.854, p<0.001$ ) and was positively correlated with weight gain ( $\mathrm{B}=0.117,95 \% \mathrm{CI} 0.076-0.158, p<0.001)$. Among the sleep related variables, only the weekend time to sleep showed a significant correlation among the factors that showed a correlation in the simple correlation analysis. In other words, as the time to sleep was delayed, the diastolic blood pressure tended to increase $(B=0.926,95 \%$ CI $0.288-1.565$; $p<0.001$ ). 
Table 3. The multivariate linear regression analysis when diastolic blood pressure is considered as the dependent variable.

\begin{tabular}{ccc}
\hline Variables & Coefficient $\mathbf{9 5 \% \text { Confidence Interval) }}$ & $p$-Value \\
\hline Sex & $0.516(-0.540-1.572)$ & 0.338 \\
Age & $\mathbf{0 . 5 6 1}(\mathbf{0 . 2 6 7 - 0 . 8 5 4 )}$ & $<\mathbf{0 0 1}$ \\
Alcohol history & $-0.106(-1.181-0.969)$ & 0.847 \\
Smoking history & $0.853(-0.515-2.222)$ & 0.222 \\
Height & $0.007(-0.066-0.081)$ & 0.850 \\
Weight & $\mathbf{0 . 1 1 7}(\mathbf{0 . 0 7 6 - 0 . 1 5 8 )}$ & $<\mathbf{0 . 0 0 1}$ \\
Weekday sleep onset time & $-0.197(-3.200-2.806)$ & 0.898 \\
Weekday wake time & $0.614(-2.264-3.49)$ & 0.676 \\
Weekday sleep duration & $0.087(-2.738-2.912)$ & 0.952 \\
Weekend sleep onset time & $\mathbf{0 . 9 2 6}(\mathbf{0 . 2 8 8 - 1 . 5 6 5 )}$ & $\mathbf{0 . 0 0 4}$ \\
Weekend wake time & $-0.484(-1.321-0.353)$ & 0.257 \\
Weekend sleep duration & $0.167(-0.247-0.582)$ & 0.429
\end{tabular}

Bold number indicates statistical significance $(p<0.05)$. Sleep onset time and wake time are presented in actual time (24-h format). However, the sleep time after midnight was presented by adding the actual time after $24 \mathrm{~h}$ in case sleep onset time. For example, 1 a.m. is marked as 25, and 2 a.m. is marked as 26. Duration of sleep is presented in hours.

\section{Discussion}

This study aimed to investigate whether the sleep time-related variables such as sleep onset time, wake time, and sleep duration were related to the blood pressure in Korean adolescents. In Korean adolescents, we confirmed a significant association between the sleep onset time on weekends and diastolic blood pressure. However, other variables related to the sleep time were not correlated with the systolic and diastolic blood pressure. In addition, the sleep duration, which is known to be related to elevated blood pressure in a previous study $[9,10]$, did not show any significant association with blood pressure in our study. Additionally, we showed that the increase in body weight was significantly correlated with the increase in systolic and diastolic blood pressure and the increase in diastolic blood pressure was significantly associated with an increase in age.

Several studies have reported a strong association between sleep deprivation and hypertension. Hwangbo et al. reported that a sleep duration of less than $6 \mathrm{~h}$ in Korean adults over 19 years had a significant relationship with the occurrence of hypertension. Notably, they showed that catch-up sleep on weekends significantly reduced the incidence of hypertension [11]. Moreover, one study reported that a short sleep duration was associated with hypertension in adolescents [12]. There have been several studies on the association between catch-up sleep on weekends and hypertension. One study reported that catch-up sleep on weekends was significantly reduced in hypertensive children by 40 min compared with the control group [13]. However, other studies have reported that a lack of weekend catch-up sleep was not correlated with hypertension but raised the risk of metabolic derangements such as type 2 diabetes and hypercholesterolemia [14]. As such, it is thought that there may be an association between sleep supplementation on the weekend and the occurrence of hypertension; however, there are insufficient studies to accept it as a consistent opinion. Therefore, additional prospective studies are needed on the association between hypertension occurrence and sleep time-related variables such as weekend catch-up sleep and sleep onset time.

However, there is still a lack of study on the effects of sleep or wake-up time on blood pressure. In this study, the sleep onset time, wake-up time, and total sleep duration were extended on weekends than on weekdays in Korean adolescents. It was observed that sleep is usually delayed with an early wake-up time in adolescents, and a short sleep duration due to schoolwork during weekdays; they compensate for this lack of sleep on the weekends. Another study of high school students in Korea reported that the average weekday sleep time was $5 \mathrm{~h}$ and $42 \mathrm{~min}$ (SD, $1 \mathrm{~h}$ ). This result shows that Korean adolescents have a short weekday sleep time compared to other countries: $8.4 \mathrm{~h}$ in Spain, 7.8 h in India, and $8.04 \mathrm{~h}$ in Germany [15]. 
As of yet, we do not know the exact biological mechanism underlying the association between a late sleep onset time on weekends and an increased diastolic blood pressure in adolescents. However, we postulate that changes in the sleep patterns on weekends (delayed sleep onset time and late wake time) might be related to blood pressure. A preceding study showed that irregular changes in the sleep time on weekdays and weekends in adolescence are associated with brain function and circadian misalignments. These factors might be related to substance abuse problems and depression [16]. Similarly, other studies have suggested that weekday and weekend sleep time inconsistencies can affect brain function, even though weekend catch-up sleep can help recover from sleep deprivation during the weekday [17]. We can see that Korean adolescents compensate for the lack of weekday sleep on weekends. However, they go to sleep later on weekends than on weekdays. It is presumed that sleeping late on the weekends makes up for the lack of play or study time during the weekdays. We postulated that the changes in the sleep patterns on weekends (delayed sleep onset time and late wake time) might be related to an elevated diastolic blood pressure. In addition, further study is needed on what clinical significance the difference in the width of the standard error of systolic blood pressure and diastolic blood pressure measurements according to each sleep time variable.

Several studies have shown the relationship between weight gain and blood pressure in adolescents. There was a significant association between the body mass index (BMI) and blood pressure in adolescents; additionally, it has been reported that the systolic and diastolic blood pressure increased with weight gain in overweight adolescents [18]. Moreover, a study reported that weight loss was a critical factor in preventing hypertension in obese adolescents [19]. As lifestyle modifications such as weight loss are essential when adolescents with hypertension are overweight or obese, weight and blood pressure also have a significant association, as shown in the results of this study [20].

The strength of this study is that the results are reliable because we enrolled many participants compared to the study objectively measured using an actigraph. Another strength of this study is that, unlike other studies, it was possible to identify detailed factors for the occurrence of hypertension in adolescents by dividing the total sleep duration, sleep onset time, and wake-up time on weekdays and weekends. However, this study had several limitations. First, it is more likely to involve subjectivity in measuring the sleep time than a study using an actigraph. Second, in the results of this study, the diastolic blood pressure was significantly associated with the sleep onset time on weekends but not with the time to sleep on a weekday. Third, since this study is a cross-sectional analysis, it was impossible to explain the mechanism of the significant association between the sleep onset time on weekends and diastolic blood pressure. Therefore, additional prospective research is needed to clarify the mechanism of the results of this study.

\section{Conclusions}

In this study, we confirmed that a delayed sleep onset time on weekends was significantly correlated with increased diastolic blood pressure in Korean adolescents. This study showed that a late sleep onset time might be a significant risk factor for hypertension in adolescents. Further study is needed on the mechanism underlying the relationship between the sleep onset time to sleep and hypertension in adolescents.

Author Contributions: Conceptualization, J.-W.K. and S.-W.C.; Funding acquisition, S.-W.C.; Data curation, S.-W.C. and J.-W.K.; Formal analysis, J.-W.K.; Validation, S.-W.C. and J.-W.K.; Investigation, S.-W.C. and J.-W.K.; Writing-original draft \& review, S.-W.C. and J.-W.K. All authors have read and agreed to the published version of the manuscript.

Funding: This work was supported by a research grant from Jeju National University Hospital in 2021. 
Institutional Review Board Statement: This research study was conducted retrospectively from data obtained for clinical purposes. We consulted extensively with the Institutional Review Board of Jeju National University Hospital who determined that our study did not need ethical approval. An IRB official waiver of ethical approval was granted from the Institutional Review Board of Jeju National University Hospital.

Informed Consent Statement: Informed consent was obtained from all subjects involved in the study.

Data Availability Statement: All available data generated or analyzed during this study are included in this published article. Other raw data are not available due to the regulation of data sharing in the Republic of Korea.

Acknowledgments: The authors are very grateful to Myong Hee Kim, Suan Kang, and Iaan Kang.

Conflicts of Interest: All authors declare no conflict of interest. The funders had no role in the design of the study; in the collection, analyses, or interpretation of data; in the writing of the manuscript, or in the decision to publish the results.

\section{References}

1. Forouzanfar, M.H.; Liu, P.; Roth, G.A.; Ng, M.; Biryukov, S.; Marczak, L.; Alexander, L.; Estep, K.; Abate, K.H.; Akinyemiju, T.F.; et al. Global Burden of Hypertension and Systolic Blood Pressure of at Least 110 to $115 \mathrm{~mm} \mathrm{Hg,} \mathrm{1990-2015.} \mathrm{JAMA} \mathrm{2017,} \mathrm{317,}$ 165-182. [CrossRef] [PubMed]

2. Olsen, M.H.; Angell, S.Y.; Asma, S.; Boutouyrie, P.; Burger, D.; Chirinos, J.A.; Damasceno, A.; Delles, C.; Gimenez-Roqueplo, A.-P.; Hering, D.; et al. A call to action and a lifecourse strategy to address the global burden of raised blood pressure on current and future generations: The Lancet Commission on hypertension. Lancet 2016, 388, 2665-2712. [CrossRef]

3. Zhou, B.; Bentham, J.; Di Cesare, M.; Bixby, H.; Danaei, G.; Cowan, M.J.; Paciorek, C.J.; Singh, G.; Hajifathalian, K.; Bennett, J.E.; et al. Worldwide trends in blood pressure from 1975 to 2015: A pooled analysis of 1479 population-based measurement studies with 19.1 million participants. Lancet 2017, 389, 37-55. [CrossRef]

4. Samuels, J.A.; Zavala, A.S.; Kinney, J.M.; Bell, C.S. Hypertension in Children and Adolescents. Adv. Chronic. Kidney Dis. 2019, 26, 146-150. [CrossRef] [PubMed]

5. Obarzanek, E.; Wu, C.O.; Cutler, J.A.; Kavey, R.E.; Pearson, G.D.; Daniels, S.R. Prevalence and incidence of hypertension in adolescent girls. J. Pediatr. 2010, 157, 461-467.e5. [CrossRef] [PubMed]

6. Cappuccio, F.P.; Miller, M.A. Sleep and Cardio-Metabolic Disease. Curr. Cardiol. Rep. 2017, 19, 110. [CrossRef] [PubMed]

7. Cappuccio, F.P.; Cooper, D.; D’Elia, L.; Strazzullo, P.; Miller, M.A. Sleep duration predicts cardiovascular outcomes: A systematic review and meta-analysis of prospective studies. Eur. Heart J. 2011, 32, 1484-1492. [CrossRef] [PubMed]

8. Chandola, T.; Ferrie, J.E.; Perski, A.; Akbaraly, T.; Marmot, M.G. The effect of short sleep duration on coronary heart disease risk is greatest among those with sleep disturbance: A prospective study from the Whitehall II cohort. Sleep 2010, 33, 739-744. [CrossRef] [PubMed]

9. Khan, M.A.; Mathur, K.; Barraza, G.; Sin, S.; Yang, C.J.; Arens, R.; Sutton, N.; Mahgerefteh, J. The relationship of hypertension with obesity and obstructive sleep apnea in adolescents. Pediatr. Pulmonol. 2020, 55, 1020-1027. [CrossRef] [PubMed]

10. Fobian, A.D.; Elliott, L.; Louie, T. A Systematic Review of Sleep, Hypertension, and Cardiovascular Risk in Children and Adolescents. Curr. Hypertens. Rep. 2018, 20, 42. [CrossRef] [PubMed]

11. Hwangbo, Y.; Kim, W.J.; Chu, M.K.; Yun, C.H.; Yang, K.I. Association between weekend catch-up sleep duration and hypertension in Korean adults. Sleep Med. 2013, 14, 549-554. [CrossRef] [PubMed]

12. Santos, E.; Souza, O.F. Evidence of the association between sleep duration and blood pressure in adolescents: A systematic review. Rev. Paul. Pediatr. 2021, 39, e2019225. [CrossRef]

13. Gupta, N.; Maranda, L.; Gupta, R. Differences in self-reported weekend catch up sleep between children and adolescents with and without primary hypertension. Clin. Hypertens. 2018, 24, 7. [CrossRef]

14. Kim, J.J.; Hwang, I.C. Weekend catch-up sleep is associated with reduced metabolic derangements in Korean adults. Neurol. Sci. 2021, 42, 735-737. [CrossRef] [PubMed]

15. Kim, S.J.; Lee, Y.J.; Cho, S.J.; Cho, I.H.; Lim, W.; Lim, W. Relationship between weekend catch-up sleep and poor performance on attention tasks in Korean adolescents. Arch. Pediatr. Adolesc. Med. 2011, 165, 806-812. [CrossRef] [PubMed]

16. Hasler, B.P.; Dahl, R.E.; Holm, S.; Jakubcak, J.L.; Ryan, N.D.; Silk, J.; Phillips, M.L.; Forbes, E. Weekend-weekday advances in sleep timing are associated with altered reward-related brain function in healthy adolescents. Biol. Psychol. 2012, 91, 334-341. [CrossRef] [PubMed]

17. Zhang, R.; Tomasi, D.; Shokri-Kojori, E.; Wiers, C.E.; Wang, G.J.; Volkow, N.D. Sleep inconsistency between weekends and weekdays is associated with changes in brain function during task and rest. Sleep 2020, 43, zsaa076. [CrossRef] [PubMed]

18. Wühl, E. Hypertension in childhood obesity. Acta Paediatr. 2019, 108, 37-43. [CrossRef] [PubMed] 
19. Hagman, E.; Danielsson, P.; Elimam, A.; Marcus, C. The effect of weight loss and weight gain on blood pressure in children and adolescents with obesity. Int. J. Obes. 2019, 43, 1988-1994. [CrossRef] [PubMed]

20. Riley, M.; Hernandez, A.K.; Kuznia, A.L. High Blood Pressure in Children and Adolescents. Am. Fam. Physician 2018, 98, 486-494. [PubMed] 